\section{(1) \\ CrossMark}

\title{
ELTGOL airway clearance in bronchiectasis: laying the bricks of evidence
}

\author{
Conroy Wong ${ }^{1}$, Cameron Sullivan ${ }^{1}$ and Lata Jayaram ${ }^{2,3}$
}

Affiliations: ${ }^{1}$ Counties Manukau District Health Board, Dept of Respiratory Medicine, Middlemore Hospital, Auckland, New Zealand. ${ }^{2}$ The University of Melbourne, Dept of Medicine, Melbourne Clinical School, Melbourne, Australia. ${ }^{3}$ Dept of Respiratory and Sleep Medicine, Western Health, St Albans, Australia.

Correspondence: Conroy Wong, Counties Manukau District Health Board, Dept of Respiratory Medicine, Middlemore Hospital, 100 Hospital Rd, Otahuhu, Auckland 2025, New Zealand.

E-mail: conroy.wongamiddlemore.co.nz

@ERSpublications

ELTGOL therapy is one of the best evidence-based airway clearance techniques for bronchiectasis http://ow.ly/vXmU30gZUSR

Cite this article as: Wong C, Sullivan C, Jayaram L. ELTGOL airway clearance in bronchiectasis: laying the bricks of evidence. Eur Respir J 2018; 51: 1702232 [https://doi.org/10.1183/13993003.02232-2017].

The thought that flickers almost as a reflex when we think about airway clearance techniques in bronchiectasis is "where is the evidence?" A solid foundation for the efficacy of treatments should be based on randomised controlled trials. Currently, the evidence base is sparse but fortunately the field has not been abandoned.

Current international guidelines recommend airway clearance techniques as part of routine management of patients with bronchiectasis [1-3]. Since impaired mucociliary clearance and sputum retention are core elements in the pathophysiology of bronchiectasis [4,5], the rationale for use of nonpharmacological interventions that facilitate removal of sputum appears reasonable. A wide variety of airway clearance techniques are available. These include postural drainage, manual techniques (percussion or clapping), breathing strategies (active cycle of breathing or autogenic drainage), positive expiratory pressure (PEP) devices and airway oscillating devices [6]. Recent Cochrane reviews evaluating the effects of these techniques have found the quality of the evidence to be low: few randomised controlled trials have been undertaken and the longest duration of intervention was 3 months $[7,8]$.

A less well known but increasingly popular technique for airway clearance is slow expiration with the glottis opened in a lateral posture or ELTGOL (L'Expiration Lente Totale Glotte Ouverte en décubitus Latéral), which was first described by Postiaux et al. [9] in 1987. In this technique, the patient lies in a lateral decubitus position and breathes out slowly through an open glottis from functional residual capacity to residual volume. The goal is to control expiratory flow to prevent airway closure and facilitate mucus clearance. In contrast to conventional postural drainage, mucus clearance is only increased in the dependent, inferiorly positioned lung [10].

Mucus is cleared from the respiratory tract by two main mechanisms: ciliary transport and expiratory airflow [11]. Many airway clearance techniques, including ELTGOL, are based on increasing airflow clearance by a mechanism known as two-phase gas-liquid flow [12]. In this model, when air flows over mucus it creates a shear force that can overcome the resistive forces in the mucus layer. The higher the

Received: Oct 302017 | Accepted: Oct 312017

Conflict of interest: None declared.

Copyright OERS 2018 
velocity of airflow the greater the shear force is. In the ELTGOL technique, the volume of the dependent lung is reduced by placing the patient in the lateral decubitus position and by limiting breathing to expiratory reserve volume [13]. This reduces total cross-sectional area of the peripheral airways where mucus is primarily produced. Since maximum airflow velocity is inversely proportional to airway diameter, the velocity of airflow in the peripheral airways is increased [14]. Airway patency is maintained by increasing intraluminal pressure via slow expiration through an open glottis [15]. Overall, this results in greater clearance of mucus from the peripheral airways [10].

In this issue of the European Respiratory Journal, MuNoz et al. [16] report results from their randomised, placebo-controlled, 12-month trial, in which they assessed the effects of twice-daily ELTGOL treatment for airway clearance in patients with bronchiectasis and chronic sputum production. ELTGOL airway clearance significantly increased overall 24 -h sputum volume (during first intervention and $24 \mathrm{~h}$ later) by $17 \mathrm{~mL}$ compared to placebo. The ELTGOL technique also increased sputum clearance, reduced symptom-based exacerbations and improved health-related quality of life after 12 months. No effects on lung function, exercise capacity, dyspnoea or inflammatory markers were noted.

It is often assumed that chest physiotherapy increases sputum clearance. However, the study by MuNoz et al. [16] is one of only two placebo-controlled studies of airways clearance techniques that have evaluated sputum volume as the primary outcome. A previous crossover study with nine participants compared oscillating PEP therapy using a flutter device with sham treatment using a flutter device without a sphere [17]. However, it is possible that the sham procedure, which involved breathing from full inspiratory capacity, could have affected the primary outcome [7]. Studies of physiotherapy interventions are notoriously difficult to blind and in the study by MuNoz et al. [16], the sham procedure used was upper-limb stretching exercises. At first glance it is obvious that the placebo control intervention is not similar to the active treatment. However, use of such a control intervention in order to avoid affecting the primary outcome may be justified if patients are adequately blinded to the treatment hypothesis [18].

The distinguishing feature of the study by MuNoz et al. [16] relative to other clinical trials is the longer duration of intervention and analysis of clinically relevant endpoints after 12 months. The health-related quality of life questionnaires, St George's Respiratory Questionnaire (SGRQ) and Leicester Cough Questionnaire (LCQ), are well established outcomes for clinical trials in bronchiectasis [19, 20]. Clinically important improvements in the SGRQ and LCQ scores were recorded in the ELTGOL group compared to the placebo group. These longer-term findings provide support for sputum volume as a clinically relevant endpoint. Fewer exacerbations were also seen in the ELTGOL group. However, caution should be taken when interpreting exacerbations in this study because a symptom-based definition has not been established as a responsive outcome measure in bronchiectasis studies. A more convincing but as yet untested consensus definition of an exacerbation based on symptoms and a change in treatment has recently been published in the European Respiratory Journal [21].

Should we now prescribe the ELTGOL intervention as the preferred airway clearance option for our patients with bronchiectasis? Arguably, it now has the strongest evidence base, albeit still limited, of all the available airways clearance techniques. Previous studies have established the physiological and biomechanical basis for treatment $[10,13]$. It is simple, inexpensive, well tolerated, able to be performed independently or with the aid of a physiotherapist [13], a reproducible technique [13], and supported by randomised clinical trials $[8,16,22,23]$. A recent randomised trial also showed that ELTGOL therapy compared favourably to two other slow expiratory airway clearance techniques (autogenic drainage and temporary PEP) [23].

When choosing from the myriad of airway clearance techniques available, it is worth contemplating for more than a moment the thought that ELTGOL therapy is one of the best evidence-based options. The foundation bricks for this technique are now well embedded but clearly further research and larger studies are required to build on the evidence, particularly for long-term patient-centred outcomes. Consideration could also be given to combining ELTGOL therapy with other evidence-based treatment modalities such as pulmonary rehabilitation and exercise training $[3,24]$.

\section{References}

1 Pasteur MC, Bilton D, Hill AT, et al. British Thoracic Society guideline for non-CF bronchiectasis. Thorax 2010; 65: Suppl. 1, i1-i58.

2 Chang AB, Bell SC, Torzillo PJ, et al. Chronic suppurative lung disease and bronchiectasis in children and adults in Australia and New Zealand Thoracic Society of Australia and New Zealand guidelines. Med J Aust 2015; 202: 130.

3 Polverino E, Goeminne PC, McDonnell MJ, et al. European Respiratory Society guidelines for the management of adult bronchiectasis. Eur Respir J 2017; 50: 1700629.

4 Currie DC, Pavia D, Agnew JE, et al. Impaired tracheobronchial clearance in bronchiectasis. Thorax 1987; 42: $126-130$ 
5 McShane PJ, Naureckas ET, Tino G, et al. Non-cystic fibrosis bronchiectasis. Am J Respir Crit Care Med 2013; 188: 647-656.

6 Flude LJ, Agent P, Bilton D. Chest physiotherapy techniques in bronchiectasis. Clin Chest Med 2012; 33: 351-361.

7 Lee AL, Burge AT, Holland AE. Airway clearance techniques for bronchiectasis. Cochrane Database Syst Rev 2015; CD008351.

8 Lee AL, Burge AT, Holland AE. Positive expiratory pressure therapy versus other airway clearance techniques for bronchiectasis. Cochrane Database Syst Rev 2017; CD011699.

9 Postiaux G, Lens E, Alsteens G. L'Expiration Lente Totale Glotte Ouverte en décubitus Latéral (ELTGOL): nouvelle manoeuvre pour la toilette bronchique objectivée par vidéobronchographie. Ann Kinésithér 1987; 14: 341-350.

10 Martins JA, Dornelas de Andrade A, Britto RR, et al. Effect of slow expiration with glottis opened in lateral posture (ELTGOL) on mucus clearance in stable patients with chronic bronchitis. Respir Care 2012; 57: 420-426.

11 Button BM, Button B. Structure and function of the mucus clearance system of the lung. Cold Spring Harb Perspect Med 2013; 3: a009720.

12 Kim CS, Iglesias AJ, Sackner MA. Mucus clearance by two-phase gas-liquid flow mechanism: asymmetric periodic flow model. J Appl Physiol (1985) 1987; 62: 959-971.

13 Lanza FC, Alves CS, dos Santos RL, et al. Expiratory reserve volume during slow expiration with glottis opened in infralateral decubitus position (ELTGOL) in chronic pulmonary disease: technique description and reproducibility. Respir Care 2015; 60: 406-411.

14 Van der Schans CP. Bronchial mucus transport. Respir Care 2007; 52: 1150-1156.

15 Voets PJ, van Helvoort HA. The role of equal pressure points in understanding pulmonary diseases. Adv Physiol Educ 2013; 37: 266-267.

16 Muñoz G, de Gracia J, Buxó M, et al. Long-term benefits of airway clearance in bronchiectasis: a randomised placebo-controlled trial. Eur Respir J 2017; 51: 1701926.

17 Figueiredo PH, Zin WA, Guimaraes FS. Flutter valve improves respiratory mechanics and sputum production in patients with bronchiectasis. Physiother Res Int 2012; 17: 12-20.

18 Boutron I, Guittet L, Estellat C, et al. Reporting methods of blinding in randomized trials assessing nonpharmacological treatments. PLoS Med 2007; 4: e61.

19 Wilson CB, Jones PW, O'Leary CJ, et al. Validation of the St. George's Respiratory Questionnaire in bronchiectasis. Am J Respir Crit Care Med 1997; 156: 536-541.

20 Murray MP, Turnbull K, MacQuarrie S, et al. Validation of the Leicester Cough Questionnaire in non-cystic fibrosis bronchiectasis. Eur Respir J 2009; 34: 125-131.

21 Hill AT, Haworth CS, Aliberti S, et al. Pulmonary exacerbation in adults with bronchiectasis: a consensus definition for clinical research. Eur Respir J 2017; 49: 1700051.

22 Guimaraes FS, Moco VJ, Menezes SL, et al. Effects of ELTGOL and Flutter VRP1 ${ }^{\circledR}$ on the dynamic and static pulmonary volumes and on the secretion clearance of patients with bronchiectasis. Rev Bras Fisioter 2012; 16: 108-113.

23 Herrero-Cortina B, Vilaro J, Marti D, et al. Short-term effects of three slow expiratory airway clearance techniques in patients with bronchiectasis: a randomised crossover trial. Physiotherapy 2016; 102: 357-364.

24 Lee AL, Hill CJ, McDonald CF, et al. Pulmonary rehabilitation in individuals with non-cystic fibrosis bronchiectasis: a systematic review. Arch Phys Med Rehabil 2017; 98: 774-82. 